\title{
BUSINESS INTELLIGENCE SUPPORT FOR SUPPLY CHAIN MANAGEMENT
}

\author{
Ricardo J. Rabelo, Alexandra A. Pereira-Klen \\ Federal University of Santa Catarina, Brazil \\ \{rabelo; klen\}@gsigma-grucon.ufsc.br
}

\begin{abstract}
This paper presents a system called $S C^{2}$, which has been developed based on the business intelligence paradigm in order to better support the management of dynamic supply chains. $S C^{2}$ is a multi-agent decision support system that offers an integrated environment for dealing with the production, distribution and sales chains. Via a lean interface based on XML and CORBA, SC $C^{2}$ can obtain reliable, timely and interoperable information from the supply chain members, comprising a number of heterogeneous information sources and legacy systems. Results are presented and discussed at the end of the paper.
\end{abstract}

\section{INTRODUCTION}

This paper presents how the management of the supply chain (SC) can be more effective and transparent making use of the business intelligence paradigm.

With the advent of the globalization, the companies have invested a lot in ways to improve its business (processes) as well as to know more about their clients and their suppliers in order to be more competitive. E-commerce sites, integration of legacy systems, more powerful communication infrastructures, etc., are examples of actions companies have taken in order to improve competitiveness. No matter the topology of the virtual organization the companies are used, all these actions have provided the companies with a basis for receiving and sending plenty of information. However, the more the companies use information, the more tough is the task to treat it in an efficient and smart way. In practice, the managers have been plunged into so many information that, in opposite to the core objective, it has brought even more difficulties for taking smart and agile decisions.

Within this scenario, the paradigm of business intelligence (BI) comes in. In general, BI can be defined as the process to get (digital) information about the company's entire business so that it can be used to provide the so-called competitive advantage (Malhotra, 00). Following this trend, systems to support BI have been put into the market in the past recent years, aiming to offer an integrated and global decision-making environment to the managers. These systems normally make use of information generated by other (legacy) subsystems, especially the Data Warehouses, i.e. typically "passive" information. In spite of the importance of this kind of systems, they fail in the sense that they do not consider real-time data from the SCs in the course of their BI analysis. This is critical as consistent decisionmaking is a must nowadays, particularly in dynamic SCs. Therefore, there is a need to provide a more balanced basis for adequate decision-making (Levi et al., 00).

This work presents a system called $\mathrm{SC}^{2}$, which offers to a SC manager a wider, integrated and user-friendly environment based on the $\mathrm{BI}$ paradigm as a support for 
the supply chain management. $\mathrm{SC}^{2}$ is one result of the IST DAMASCOS project (DAMASCOS), whose ultimate goal was to develop an open and low cost platform and management services for SMEs in the fashion industry.

The paper is organized as follows: Chapter 2 gives an overview of the difficulty to manage the supply chain. Chapter 3 provides a general description of the DAMASCOS and $\mathrm{SC}^{2}$ approaches. Chapter 4 shows some implemented results of $\mathrm{SC}^{2}$. Chapter 5 discusses the results achieved and the next steps.

\section{PROBLEM DESCRIPTION}

One significant problem the enterprise has to manage SCs is to handle the enormous amount of information about and from its members (pre-suppliers, suppliers, the main producer itself, distributors, sales agents, retailers, and so on) and hence to coordinate the current (distributed) business they all are involved in. Demand, production capacities, stocks, material flow are some of the information data that should be quickly analyzed to attend an even more and more demanding market.

In more dynamic SCs, the core partners do not remain the same for a long period of time, and each one of the partners uses to participate in several SCs simultaneously. Thus, the SC management is being driven by the information related to each business, where the various relationships between the business processes can be coordinated as well as the material and the product flows can be constantly monitored. Figure 1 shows how complex this task can be even for a relatively small scenario. It is composed of ten SC members (1 pre-supplier, 4 suppliers, 1 principal producer, 1 sales agent and 3 retailers) and only five end-products. The thickest arrows indicate the information flow and the material flow.

As it can be noted, the complexity in the management increases "exponentially" with the number of supply chain members and end-products (and the quantity of its sub-components). The SC ${ }^{2}$ (Supply Chain Smart Co-ordination system) (Rabelo et al., 02) has been developed to collect, to analyze, and to organize the information about the SCs, as well as to supervise the operational phase of the business and to support the SC Coordinator in decision-making.

\section{THE SC ${ }^{2}$ APPROACH}

$\mathrm{SC}^{2}$ is a typical "information consumer" system. In order to support the BI concept, $\mathrm{SC}^{2}$ assumes that each node (member) of the $\mathrm{SC}$ is able to provide selected data through the Internet. It assumes that each enterprise has a sufficient communication infrastructure and integrated services to support the inter-enterprises cooperation.

The DAMASCOS suite (Ferreira et al., 00), for instance, corresponds to a set of cooperation services, which are carried out by specific software modules. This suite is added and integrated on the top of the enterprises' legacy systems. Within the DAMASCOS suite - and from the SC co-ordination and BI perspective - $\mathrm{SC}^{2}$ is on the top of the hierarchical architecture of DAMASCOS. On the bottom, there are the modules $S A L S A$ (for sales support), $D_{3} S_{2}$ (for forecasting purposes), IDLS (support for individual logistics), and IPO (support for some level of production management). At the middle level, there is the WfBB (a workflow system, which controls the inter-modules and inter-enterprises information exchange). Therefore, all these modules act as an intelligent front-end between the $\mathrm{SC}^{2}$ and the legacy systems. Figure 2 illustrates the global $\mathrm{SC}^{2} / \mathrm{DAMASCOS}$ framework. 


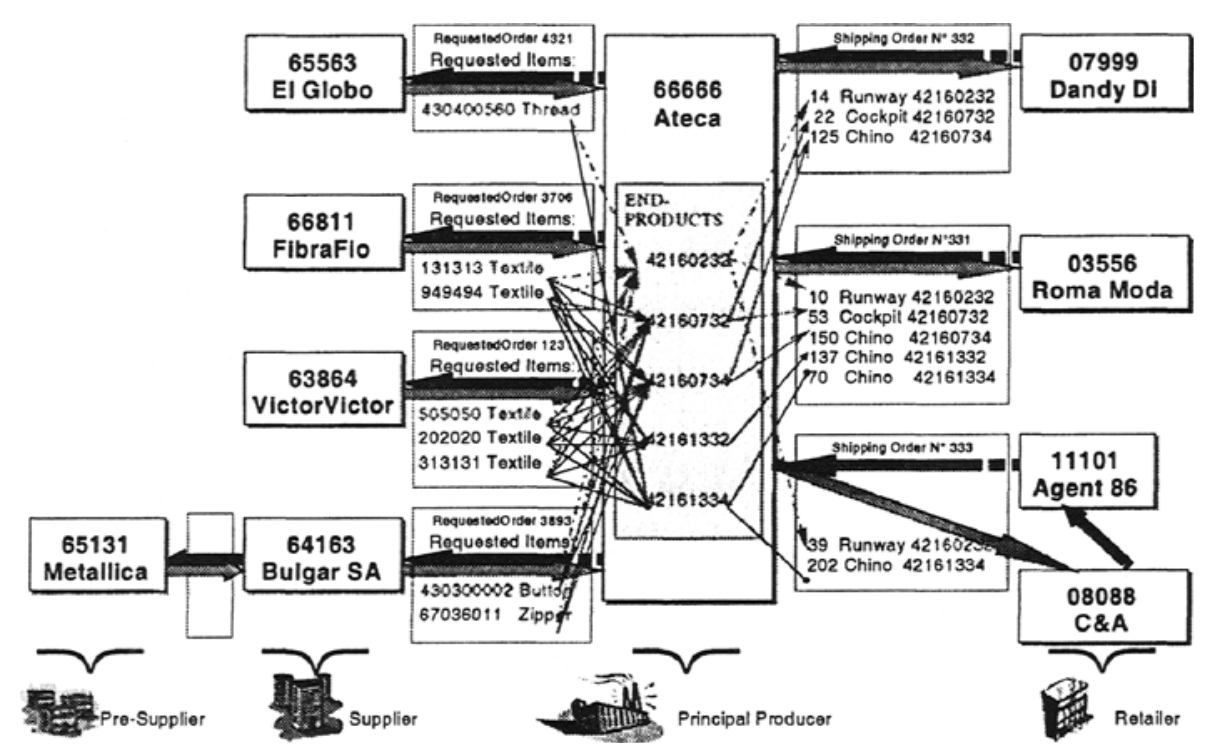

Figure 1 - Material and Information Flow of a Supply Chain

In this sense, $S C^{2}$ manages heterogeneous data provided by the heterogeneous legacy systems from each heterogeneous different SC members. Each of the DAMASCOS modules has its local database. The modules are integrated to the enterprise's database, which in turn is fed by its internal systems ${ }^{1}$. Besides that, some modules offer ASP services (to the other modules) so that some selected data from the enterprise's database can be accessed via a browser.

The DAMASCOS suite is to be installed at each SC member, regarding that its composition is configurable according to the enterprises' characteristics and needs. For instance, if a given enterprise do not manufacture anything, then the IPO module is not used. In the case of $S^{2}$, it is presented in all the SC members. However, there are two "levels" of the $\mathrm{SC}^{2}$ system. The full set of the $\mathrm{SC}^{2}$ services are only enabled when the SC member acts as the SC coordinator / main producer. A small subset of its services is then enabled when they are not coordinators, i.e. they act as suppliers, distributors, etc. (this issue is stressed in more details in the next chapter).

\subsection{SC $^{2}$ System as a Business Intelligent Support}

According to (Levi et al., 00), a number of features can characterize a system for BI support, such as: extraction and integration of data from multiples / heterogeneous sources; usage of experience and knowledge; analysis of data by multiple views; work with simulation and hypothesis; searching for cause-effects relations; transformation of passive data into useful knowledge.

The essential objectives of the $\mathrm{SC}^{2}$ is to offer to the manager/principal producer an integrated environment that provides reliable and timely information about the production, distribution and sales perspectives of these chains for smart and agile decision-making - an important key to improve the enterprise competitiveness.

A complete BI system for dealing with SCs should support functionalities to comprise the SC life cycle, i.e. the activities involved in the SC creation, configuration, operation and dissolution (Camarinha-Matos et al., 00). At the current 
stage of developments, the $\mathrm{SC}^{2}$ system is more concentrated in the second and third phases, reflected into the following macro inter-related / integrated functionalities:

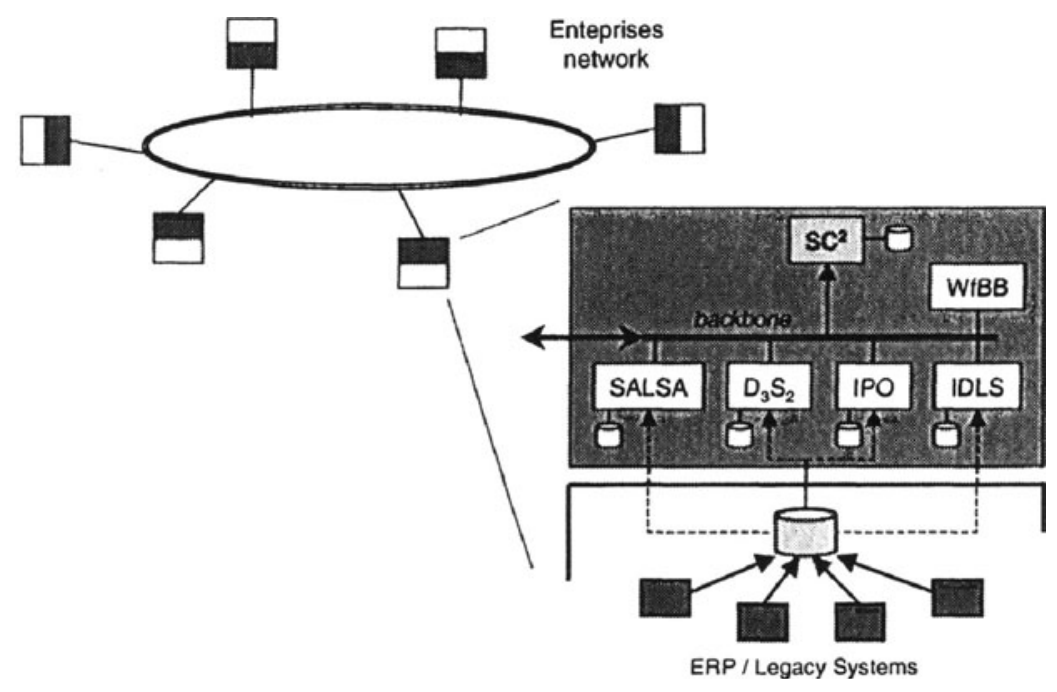

Figure $2-\mathrm{SC}^{2}$ Framework for Business Intelligence Support

- Supply Chain Configurator

Graphical and interactive specification of the "actors" of the SC, comprising their roles and inter-relations. It is the kick-off action to activate the other functionalities after the SC is created. Figure 3 shows an example of its graphical interfaces, semi-automatically created after each member of a given $\mathrm{SC}$ sends some predefined information.

- Supply Chain Smart Map

Once the SC is started, this functionality aims to offer to the SC coordinator a graphical and easy-to-use possibility of seeing the production, distribution and sales stages and their main characteristics. Its main graphical interface is quite similar to the one showed in the figure 3. However, here it is possible to get information about the SC as a whole as well as about the SC members.

- Ad Hoc Report

It aims to provide the SC coordinator with detailed information on specific areas of performance for consistent decision-making. There are two types of reports:

- Diagnostic report: it provides "real-time" information about the SC so that the SC coordinator can feel more confident in the decision-making. It comprises the sales, the production and the distribution chains. These information are organized in several "views", such as the end-products involved, the business processes, the SC Members per products and subcomponents, etc. (Figure 4). In the case the coordinator wishes to go into the legacy systems' database, "WWW doors" to their ASP functions are automatically instantiated (previously configured) in the interfaces.

- Position paper: it is triggered when a problem is identified during the SC operation. Alternative courses of actions (such as rescheduling) and probable consequences are drawn up based on decisional protocols (previously) modeled from the SC principal producer. 
- Demand Driven

The distribution and sales chains are an independent environment where uncertain customer demand determines independent inventory requirements. This functionality allows a faster reaction to conflicts observed in the end product's inventory.

- Distributed Business Process Management

It is a decision-support functionality that helps the manager in solving problems from the production perspective (Pereira-Klen et al., 01). By means of an intensive information gathering from the $\mathrm{SC}$, a periodic follow up of orders is made as well a set of alternatives schedules are suggested in the presence of problems in the SC schedule (Figure 5).

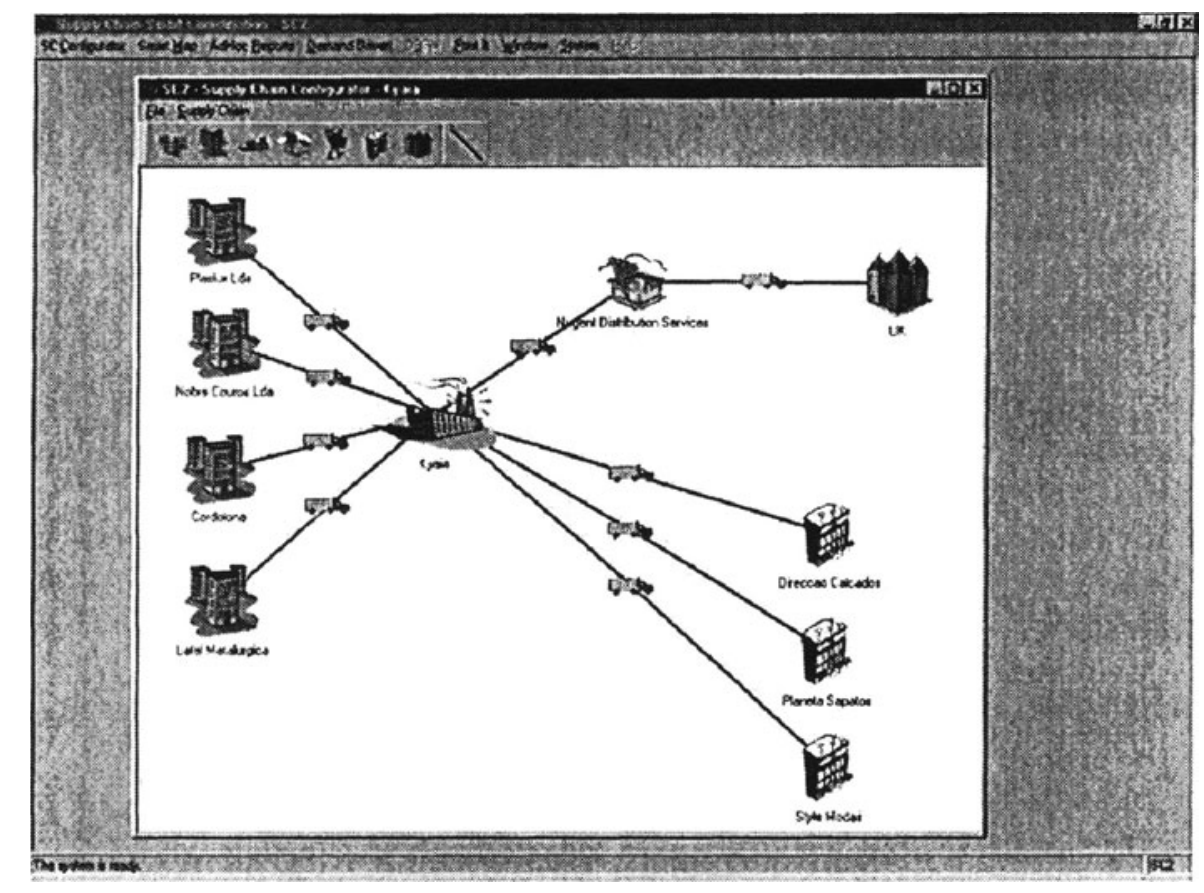

Figure 3 - Example of the SC Configuration Phase

According to the functionalities described above, the BI concept is "inserted" in the $\mathrm{SC}^{2}$ in different levels offering support for SC management. The synergy between the $\mathrm{BI}$ paradigm and the $\mathrm{SC}^{2}$ can be better understood if one consider that - in different levels - in the following sense: i) support of orders along the SC; ii) collaborative decision-making in the production chain; iii) lean integration of heterogeneous and distributed systems; iv) support for inventory planning and forecasting at the SC level; v) flexible SC (re)configuration; vi) simulation and analysis of problems; vii) global and unified environment for decision-making, and viii) storing of organized historical data.

\section{SC $^{2}$ ARCHITECURE AND IMPLEMENTATION ISSUES}

$S C^{2}$ is a decision support system that manages the distributed business process of a dynamic supply network by means of real-time monitoring and supervision 
activities. It facilitates the conflict analysis and its resolution supported by decisional protocols, providing a human-centered smart coordination of the SC.

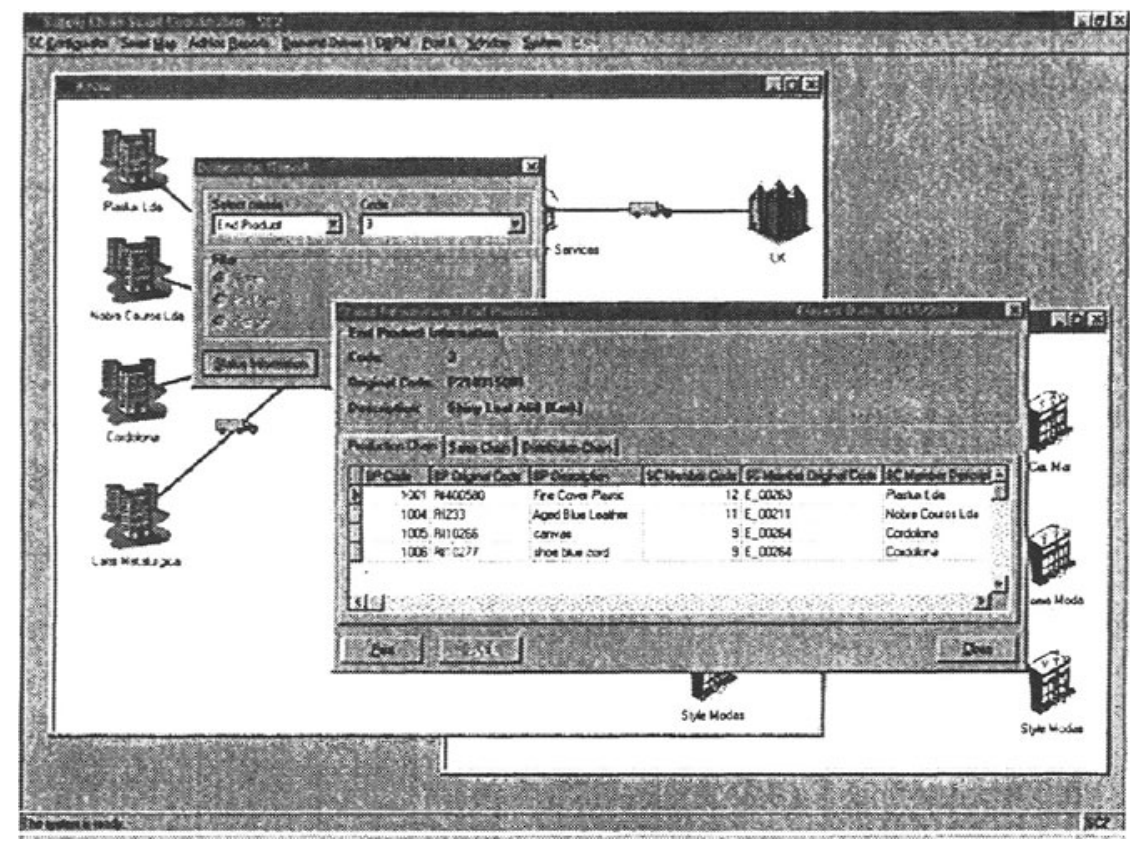

Figure 4 - Example of an AdHoc Report

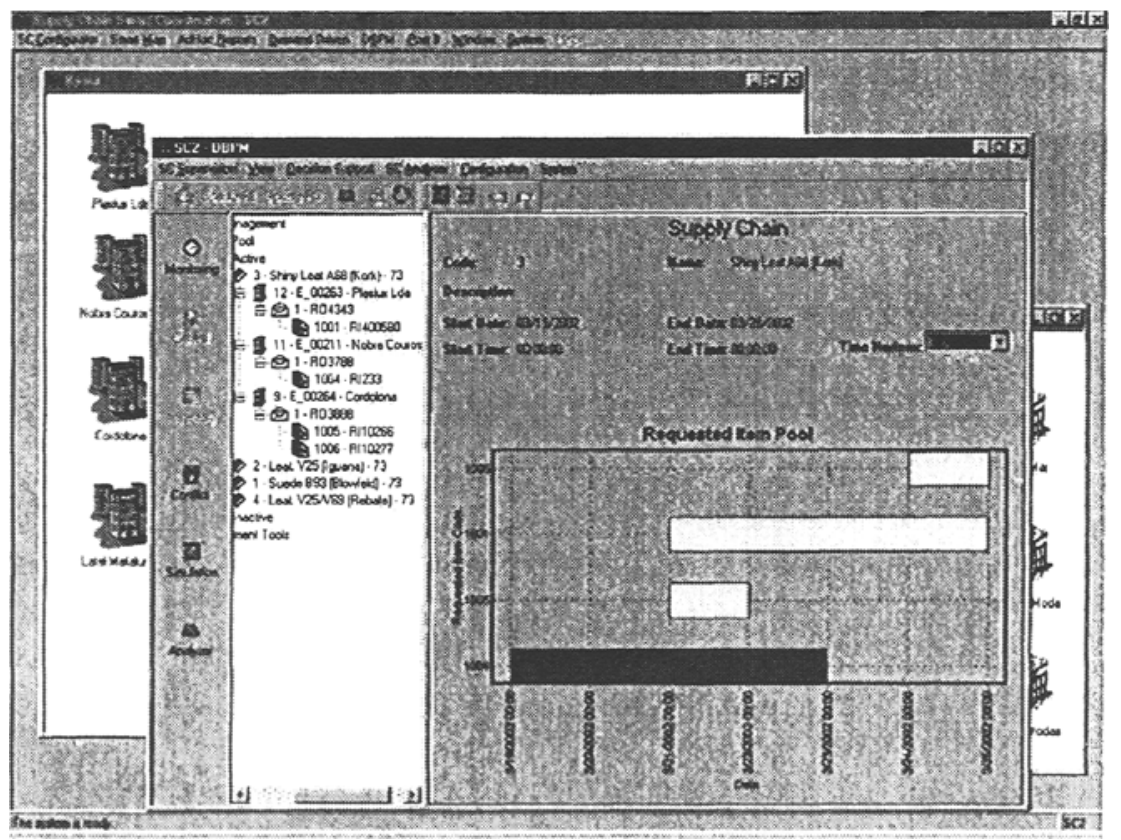

Figure 5 - Example of the Orders Follow Up \& Simulation of Alternatives

$\mathrm{SC}^{2}$ is multi-agent system. This technology has been used because it supports the main $\mathrm{SC}^{2}$ requirements, namely: (i) the $\mathrm{SC}^{2}$ agents can be launched in distributed PCs; ii) as problems use to occur along the SC operation, the agents can work based on flexible constraints relaxation; iii) new knowledge can emerge from the agents 
cooperation hence providing smarter decisions; iv) other agents / supply chain perspectives can be added into the $\mathrm{SC}^{2}$ without altering its control architecture; and v) each perspective of the chain is managed in/by an autonomous way/agent.

The $\mathrm{SC}^{2}$ system is composed of five agents (figure 6): Smart Agent (responsible for the global SC management), Production Agent, Sales Agent and Distribution Agent (responsible for dealing with the production, sales and distribution individual chains, respectively), and the XML Agent (responsible for dealing with the communication among the agents and with the "external environment"). All the functionalities addressed in the previous section are carried out by these agents. However, this is totally transparent to the end-user.

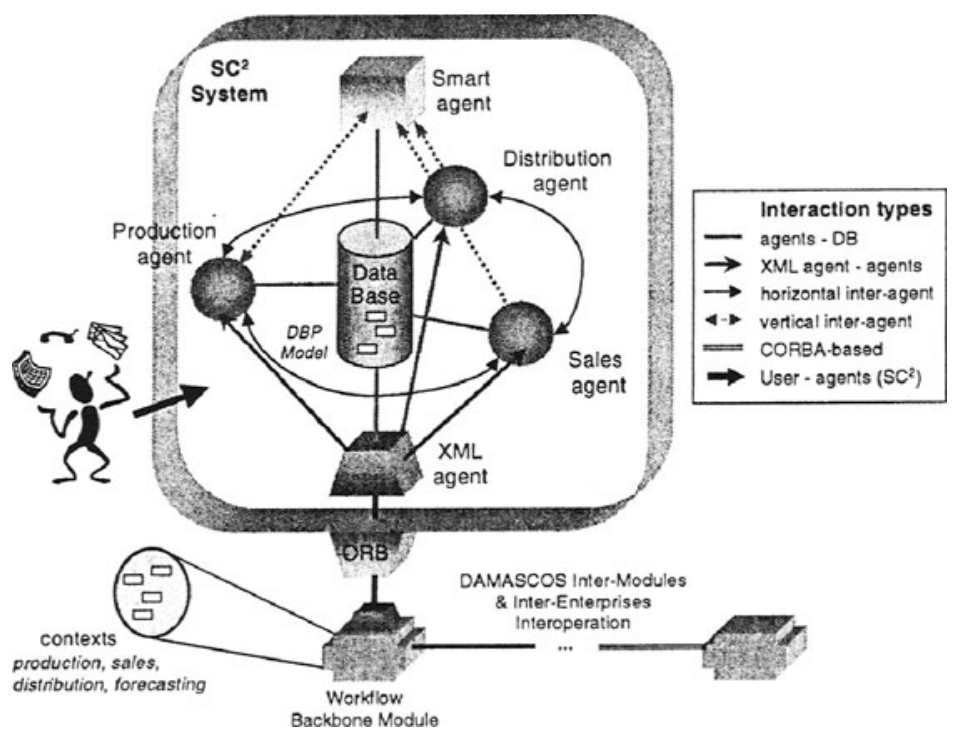

Figure 6 - The $\mathrm{SC}^{2}$ Architecture

The $\mathrm{SC}^{2}$ implementation model combines multi-agent systems, CORBA, XML, databases, and decision support systems. $S^{2}$ receives the required information from the IPO, IDLS and SALSA modules via the WfBB module, regarding the "contexts". Each of these contexts corresponds to a XML DTD, accessed by a SC"'s ORB specific service. Once the information is obtained, it is sent and managed by the XML agent, which parsers the XML message received and makes a matching with the DTD "reference". After this pre-processing, the information is encapsulated as an object and sent to the $\mathrm{SC}^{2}$ database. The involved DBMS stores it in a reference data model called Distributed Business Process (DBP) Model (PereiraKlen et al, 01). In parallel, the XML agent sends a message to the Production, Sales and Distribution agents so that they can be aware about the arrival of updated information. Thus, the agents access the information only when they need.

$S C^{2}$ has been developed in a low cost platform: $P C /$ Windows $-N T / C++$. Free software and standards have been used as much as possible, regarding systems efficiency, configurability and interoperability. The C++ CORBA ORB TAO (TAO) has been chosen, and the system is modeled in $U M L$. The multi-agent infrastructure has used the MASSYVE KIT (MASSYVE). The (shareware) Interbase database has been utilized, with a simple object-oriented layer to allow the agents to have access to the database as objects and not as table structures. 


\section{CONCLUSIONS AND NEXT STEPS}

This paper presented the $\mathrm{SC}^{2}$ (Supply Chain Smart Coordination) system, a system to manage dynamic supply chains making use the business intelligence paradigm.

This work has been developed in the scope of the IST DAMASCOS project, evaluating the market trends, as well as based on an extensive research of related projects and the end-users' requirements. Besides that, it was conceived taking into account the supply chain life cycle, hence prepared for further extensions.

$\mathrm{SC}^{2}$ is a widely integrated system. It manages heterogeneous data provided by the heterogeneous legacy systems from each heterogeneous supply chain members, basically supported by a workflow-driven module and the use of XML and CORBA. The system offers some innovations concerning current BI systems, such as global integration of the whole supply chain as well as the involvement of several nonpassive information sources. The real-time information obtained from the supply chain members is properly modeled/selected and presented in graphical interfaces so that the manager can take decisions in an easier, smarter and more agile way.

Additionally to the results already achieved, there are some new improvements planned to be done in a short new future: integration of a partners' search and selection functionality into the $\mathrm{SC}^{2}$; the replacement of the sockets-based internal communication among the $\mathrm{SC}^{2}$ agents by a CORBA platform; introduction of more sophisticated heuristics to support global inventory planning; access rights configuration upon the smart map; and finally, the evaluation a more sophisticated information management system for dealing with the whole information of the supply chain and systems, without centralization or information redundancy.

\section{ACKNOWLEDGMENTS}

This work has been supported by $\mathrm{CNPq}$ - The Brazilian Council for R\&D - project n.480101/00-0. Thanks to M.Sc. Edmilson Rampazzo Klen, Mr. André Jacomino, Mr. Fabiano Baldo, and Mr. Rui Tramontin Jr. for the system implementation.

\section{REFERENCES}

1. Camarinha-Matos, L.M.; Afsarmanesh, H.; Rabelo, R. J., Supporting Agility in Virtual Enterprises, in E-Business and Virtual Enterprises, Eds. L. M. Camarinha-Matos, H. Afsarmanesh, and R. J. Rabelo, Kluwer Academics, pp. 145-156, 2000.

2. DAMASCOS, http://bart.inescn.pt/ damascos.

3. Levi, D.S.; Kaminsky, P.; Levi, E.S., Design. and Managing the Supply Chain, McGraw-Hill, 2000.

4. Ferreira D., Ferreira H., Ferreira J. J., Goletz T., Levin B., Holst A., Gillblad D., Ferraz R., Lopes F., Antunes N., Pereira Klen A., Rabelo R., A Workflow-Based Approach to the Integration of Enterprise Networks, Proceedings CARS \& FOF 2000, Port of Spain, Trinidad, 2000.

5. MASSYVE, http://www.gsigma-grucon.ufsc.br/massyve.

6. Pereira-Klen, A.; Rabelo, R. J.; Ferreira, A. C.; Spinosa, L. M., Managing Distributed Business Processes in the Virtual Enterprise, Journal of Int. Manuf., ISSN 09565515, V12, April 2001.

7. Rabelo, R. J.; Pereira-Klen, A.; Klen; E. R., A Multi-agent System for Smart Coordination of Dynamic Supply Chains, to be presented in the PRO-VE'2002 $3^{\text {rd }}$ IFIP Working Conference on Infrastructures for Virtual Enterprises, Portugal, May 2002.

8. TAO, http://www.cs.wustl.edu/ schmidt/ACE.html.

9. Malhotra, Yogesh, Knowledge Management and Virtual Organizations, Idea Group Publishing, USA, 2000.

\footnotetext{
'This integration approach with the legacy systems corresponds to the one implemented in the pilots of the project.
} 